\title{
Differential growth of Euplotes vannus fed fragmented versus unfragmented chains of Skeletonema costatum
}

\author{
Gerard M. Capriulo, Richard A. Schreiner*, Barbara L. Dexter \\ Division of Natural Sciences, State University of New York, Purchase, New York 10577, USA
}

\begin{abstract}
The major food source of marine ciliates has traditionally been thought to consist of small nano-sized prey items (including diatoms), and bacteria. Larger prey, including chain-forming diatoms, have been considered important dietary items for certain ciliates, particularly larger benthic species, but may provide a source of nutrition for a wider range of ciliate species if they are first modified in nature by feeding or environmental turbulence-related fragmentation. Such fragmentation of diatom chains by microcrustaceans has been documented in the literature. To begin to examine what effects algal fragmentation might have on ciliate growth, several experiments were conducted in which Euplotes vannus were presented with equal amounts of fragmented and unfragmented Skeletonema costatum as food. In all cases, growth of the ciliates was enhanced in the presence of the fragmented food.
\end{abstract}

It is known that ciliates, especially benthic forms, can ingest cells their own size and larger (Kahl 1935, Smetacek 1981). Ingestion of diatoms has been reported for hypotrich, heterotrich, gymnostome, trichostome, hymenostome, odontostome, oligotrich and choreotrich ciliates found associated with benthic sediments (Borror 1963, Fenchel 1968, 1969, 1987). For planktonic ciliates, Verity \& Villareal (1986) found that tintinnid ciliates could ingest certain diatoms lacking spiny projections, and obtain levels of nutrition sufficient for growth. Smetacek (1981) observed Strombidium spp. with protruding ingested cells, at times larger than the ciliate predator. Strombidium sp. has also been observed with large numbers of diatoms in its food vacuoles (Fenchel 1987). Nonetheless, current marine microbial food web models rarely consider potential pathways between diatoms, particularly chain-forming species, and ciliates. This is primarily due to the differences in their relative sizes, with many diatoms or their composite chains being in size equal to, or larger than, many ciliates.

- Present address: Long Island Sound Taskforce (Oceanic Society), 185 Magee Ave., Stamford, Connecticut 06902, USA
Various disruptive mechanisms, both biological and physical, exist in nature, by which natural food assemblages, including diatom chains, can have their size distribution altered toward a lower mean. For example, routine and episodic turbulent mixing of sediment in coastal waters might fragment cells. Additionally, estuarine copepods have been observed to modify large single cells and chain-forming diatoms, both in laboratory cultures and natural particle assemblages, during feeding, resulting in a higher final concentration of small particles (O'Connors et al. 1976, Deason 1980, Roman \& Rublee 1980). Many of the particles so produced are of a size that could easily be ingested by ciliates. Thus particle modification may represent a pathway by which large single-celled or chain-forming algae become available to both planktonic and benthic protozoan predators at a more 'palatable' size. Such a pulse of appropriatelysized food might enhance their growth.

The hypothesis that fragmentation of diatom chains enhances ciliate growth rate, by providing them with food items that would otherwise be unavailable to them, was tested using the hypotrich marine ciliate Euplotes vannus Müller, and the chain-forming diatom Skeletonema costatum.

Euplotes vannus was chosen as the test organism for this study primarily because it readily associates with surfaces. This behavior insured that the non-motile Skeletonema costatum cells (which accumulated on the bottom of the spot plate wells used in these experiments) would remain available to the ciliate predator. E. vannus is a behaviorally multidimensional organism found in a plethora of habitats including surface and interstitial marine benthic habitats, salt marshes, estuarine plankton and littoral zone assemblages, as well as in freshwater lake, pond and stream plankton, neuston and benthos (Bamforth 1985), and marine snow (Caron et al. 1982). 
Materials and methods. Cultures of Euplotes vannus lobtained from A. Repak, Quinnipiac College, Hamden, Connecticut, USA), Dunliella tertiolecta and Skeletonema costatum (from Guillards's Bigelow Laboratory collection, Maine, USA) were maintained in DV medium (Provasoli 1963) adjusted to a pH of 7.5 to 7.8 , in $125 \mathrm{ml}$ flasks for the ciliates, and in $30 \mathrm{ml} \mathrm{screw}$ cap test tubes for the algae. Expt 2, however, employed S. costatum cultures isolated (by G.M.C.) from western Long Island Sound, New York, USA, in February 1986. $E$. vannus cultures were kept at room temperature and the algae at $18^{\circ} \mathrm{C}$ under a $14 / 10 \mathrm{LD}$ cycle. Prior to an experiment $E$. vannus were maintained on a diet of D. tertiolecta. All experiments were run at room temperature using exponentially growing $S$. costatum as food.

Skeletonema costatum chains were fragmented using a sand vortexing technique. Beach sand (from Shinnecock beach, Long Island) was cleaned of organics by soaking in $10 \% \mathrm{HCl}$ for $24 \mathrm{~h}$, followed by a rinsing in organic-free, deionized water (ODW), a subsequent soaking in a weak $\mathrm{NaOH}$ bath, and a final ODW water rinse. The cleaned sand was then oven dried. Diatom chains were modified by introducing $3 \mathrm{ml}$ of sand into a $30 \mathrm{ml}$ screw-capped test tube, adding $7 \mathrm{ml}$ of $S$. costatum culture, and vortexing at a standard 4 setting, for $60 \mathrm{~s}$ using a Vortex-Genie. This procedure was repeated and the treatments pooled to provide about $40 \mathrm{ml}$ of treated culture. For the controls, $7 \mathrm{ml}$ of $S$. costatum was added to $3 \mathrm{ml}$ of sand without subsequent vortexing. Instead, the tube was gently inverted twice to mix sand and culture. This procedure was repeated until about $40 \mathrm{ml}$ of control culture was achieved. Cell counts were then taken for both control and treatment cultures. Numbers of cells per chain and total numbers of chains were recorded for each culture. Control suspensions were diluted with DV medium, when necessary, to equalize control and experimental algal concentrations. The above method effectively modifies long chains to shorter ones (Figs. 1A, B).

After modification, control and treatment Skeletonema costatum cultures were transferred to individual spot plate wells $(0.70 \mathrm{ml}$ per well). Ciliates from stock cultures were then introduced, 1 individual per well, into the spot plates, via micropipetting. Prior to introduction into experimental spot plate wells, each ciliate was taken through 3 washes of sterile DV to remove the Dunaliella tertiolecta cells. Cover slips were then placed over each plate well onto a thin encircling bead of Dow Chemical stopcock grease, to prevent evaporation while permitting the exchange of respiratory gases.

The experiments utilized 2 plates (9 wells per plate, i.e. 18 replicates) for each control (unmodified diatoms) and treatment (modified diatoms) condition (Expt 1 treatment condition employed 15 replicates). All data represent averages per well based on the 15 or 18 replicates. Ciliate numbers per well were followed over time for both controls and treatments, using a Wild M-5 dissecting microscope set on dark field. Their numbers at times exceeded 40 cells per well and occasionally had to be fixed at the termination of an experiment to ease counting. After completion of an experiment, numbers and distributions of Skeletonema costatum chain lengths were measured. A minimum of 50 cells was counted for the initial samples. This was not possible for post-experimentation treatment samples, since most cells had been eaten during the experiment (Figs. $2 \mathrm{~A}, \mathrm{~B})$. In these instances 2 full hemacytometer grids (4 fields, volume $=9 \times 10^{-4} \mathrm{ml}$ ) were counted.

Growth rates were calculated using the instantaneous growth equation $N_{t}=N_{0} \mathrm{e}^{r l} t$ (Capriulo et al. 1983) repetitively for each time interval, as an initial value differential equation. By solving for $r$ one interval at a time, it is necessary to assume that growth is exponential with a fixed value of $r$ only for that interval. For the next interval $r$ may take on any new value. In this way changes in $r$ over time can be studied.

Results. The vortexing of the Skeletonema costatum cultures produced a distribution of cells dominated by single cell and 2 cell-long chains, with some 3,4 or 5 cell-long chains also present (Figs. 1A, B). This represented a major redistribution of chain lengths and provided Euplotes vannus with an altered food size spectrum, relative to the control cultures. In both experiments, ciliates provided with this modified food sustained higher numbers (Figs. 1C, D) and exhibited higher growth rates (Figs. 1E, F) than those ciliates fed unmodified food. The control and treatment density response data were different from each other at the 0.09 and 0.005 levels of significance for Expts 1 and 2, respectively, based on the Wilcoxon 2-sample test for differences in ranked observations (Sokal \& Rohlf 1969).

The average cumulative numbers of ciliates in Expt 1 reached a peak of 14.93 per well $( \pm S E=2.76)$ for the treatment and $10.22( \pm \mathrm{SE}=1.82)$ for the controls, with corresponding average instantaneous growth rates (r) over the $230 \mathrm{~h}$ experiment of 0.015 and $0.010 \mathrm{~h}^{-1}$, respectively. Initially both control and treatment responses were similar. A deviation in growth rates began on the 3 rd day. Differences in growth between treatment and control wells were greatest at this time, with $r=0.0346$ and $0.0190 \mathrm{~h}^{-1}$, respectively. By the 5th day of observation no differences in $r$ values could be detected, probably due to food limitations. The analogous values for Expt $2(t=65 \mathrm{~h})$ were 29 $( \pm \mathrm{SE}=2.29)$ and $19( \pm \mathrm{SE}=1.07)$ ciliates per well for treatment and control, with respective average $r$ 's of 0.045 and $0.040 \mathrm{~h}^{-1}$. The largest difference in $r$ values 

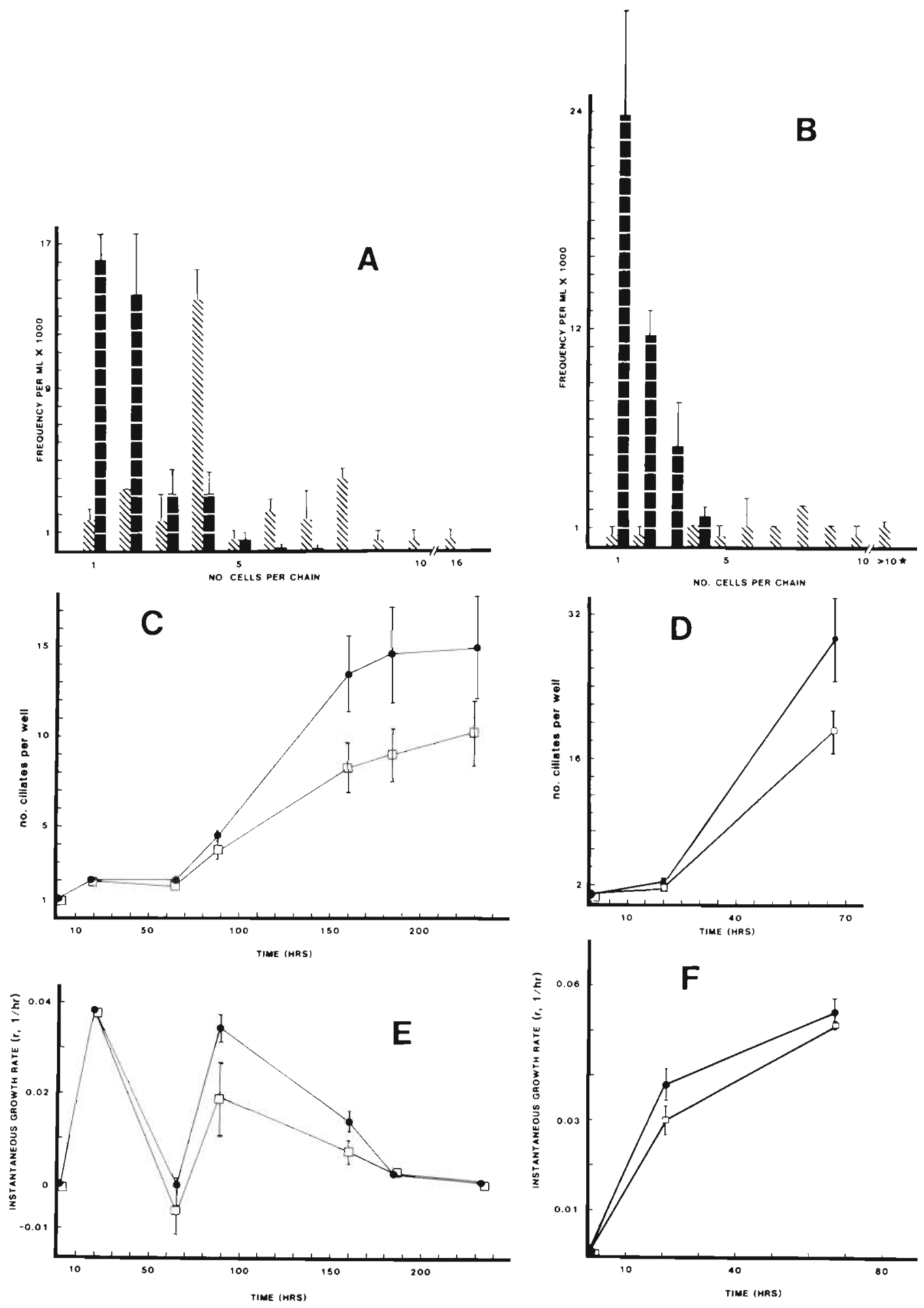

Fig. 1. (A, B) Skeletonema costatum. Mean frequency $\times 1000( \pm \mathrm{SE}) \mathrm{ml}^{-1}$ of chain lengths in treated (vortexed, horizontally striped bars) and untreated (diagonally-striped bars) cultures for Expts 1 and 2 respectively. Concentrations are those prior to dilution of the untreated algae. Such dilution equalized control and treatment concentrations before each experiment. $\star$ Total concentration of cells with $>10$ cells per chain group $=113 \times 10^{3}$ cells ml ${ }^{-1}$. (C, D) Euplotes vannus. Average ( \pm SE) change in numbers per spot plate well, over time, when fed equal volumes of treated $(\bullet$ ) and untreated (ㅁ) $S$. costatum cultures, for Expts 1 and 2 respectively. $(E, F) E$. vannus. Average $( \pm S E)$ instantaneous growth rates $\left(r, h^{-1}\right)$ over time when fed treated $(\bullet)$ and untreated (ㅁ) food for Expts 1 and 2 respectively 

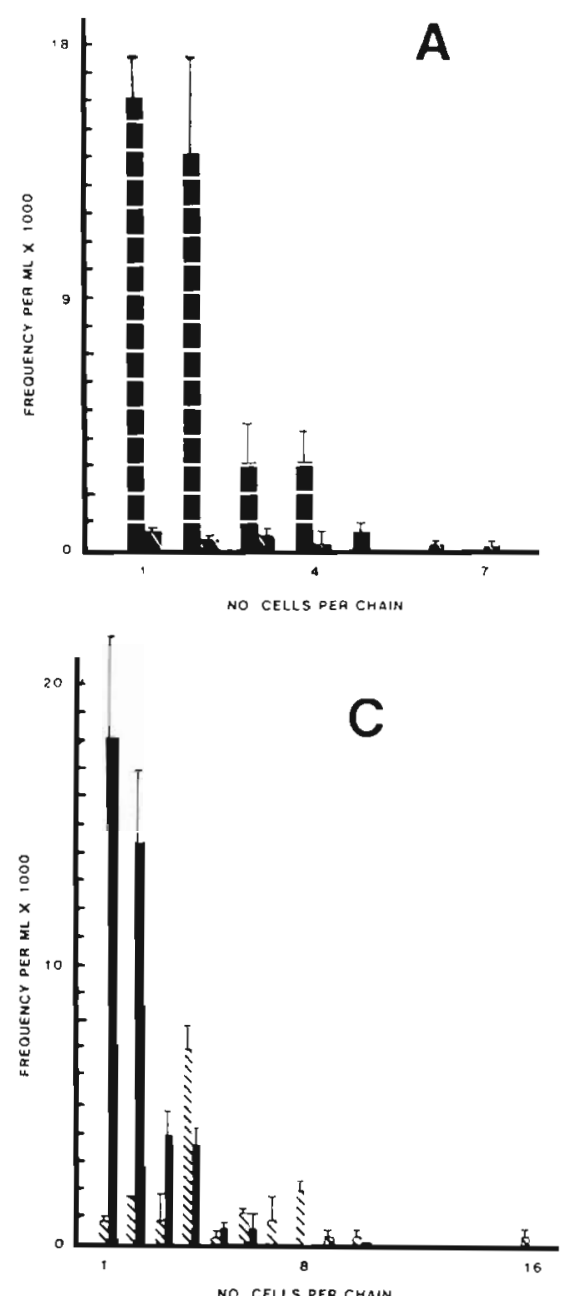

NO. CELLS DER CMAIN

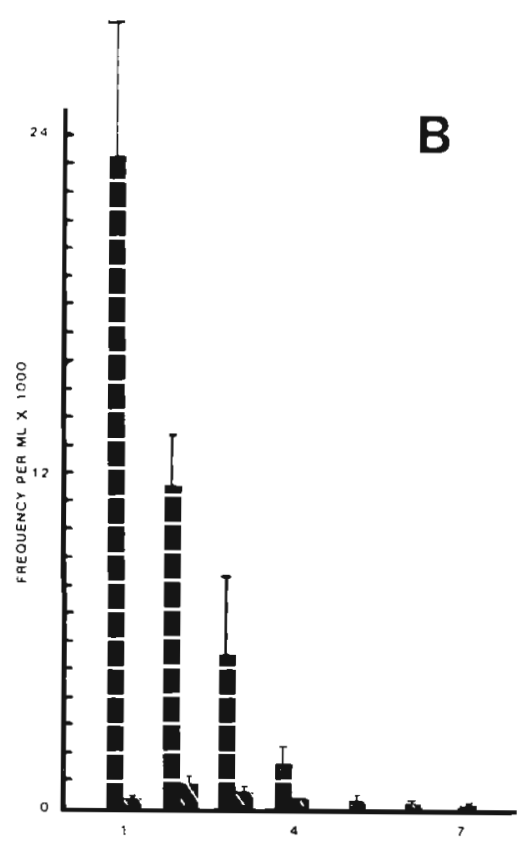

No. CELLS PER CMAin

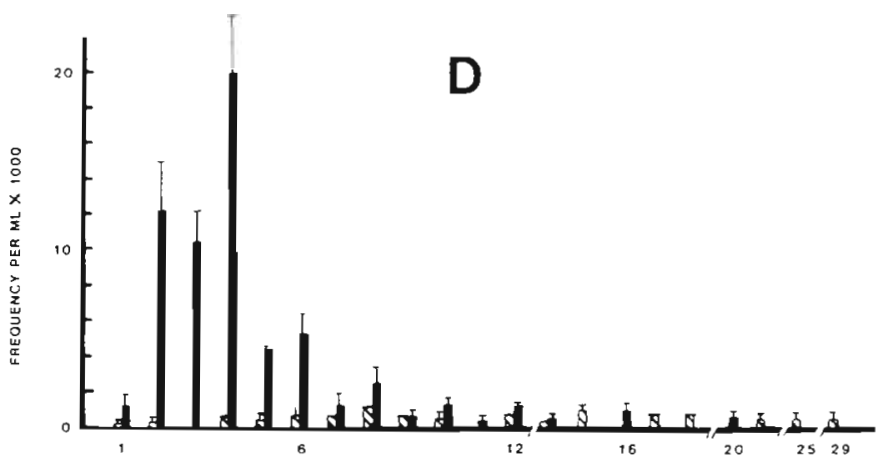

NO CELLS PER CHAIN

Fig. 2. Skeletonema costatum. (A, B) Mean frequency $\times 1000$ ( \pm SE) $\mathrm{ml}^{-1}$ of chain lengths at the start of (horizontally striped bars) and at the termination of (diagonally striped bars) an experiment under the treatment food regime, for Expts 1 and 2 , respectively. Note the extremely low numbers of short chain length at the end of each experiment. (C, D) Mean frequency $\times 1000$ ( $\pm \mathrm{SE}$ ) $\mathrm{ml}^{-1}$ of chain lengths at the start of (striped bars) and at the termination of (solid bars) an experiment under the unmodified food regime, for Expts 1 and 2 respectively. Note the higher final concentration of short chain lengths at the end of each experiment

for this experiment was observed after $20 \mathrm{~h}$ when $r=0.040$ for the treatment and 0.030 for the control.

Prior to experimentation the modified diatoms showed high numbers of 1 and 2 cell-long chains (Figs. $1 \mathrm{~A}, \mathrm{~B})$. At the termination of an experiment few Skeletonema costatum chains (or skeletal remains) of any length were present (Figs, 2A, B), suggesting intensive ciliate grazing pressure. Data for the unmodified controls indicated an increase in the number of 1 to 4 cell-long chains in both experiments (Figs. 2C, D) which may be indicative of ciliate modification of chain lengths.

Discussion. An unrecognized food web pathway may exist in nature by which larger food items, such as chain-forming diatoms, are made available to small predators, such as ciliates, by the prior modification of particles during feeding (e.g. by microcrustaceans) or by the fragmenting action of suspended sediment propelled by coastal zone turbulence (e.g. storm- and wind-generated events). Turner et al. (1983) observed a significant negative relationship between length of diatom chains and numbers of smaller zooplankton over a year cycle in a temperate zone estuary (Peconic Bay, New York, USA) suggesting that such modifications may be occurring in the field. The present data indicate that some ciliates experience enhanced 
growth when feeding on size-modified, short chains of Skeletonema costatum. Sustained numbers of Euplotes vannus offered the modified $S$. costatum were always higher than those exposed to unmodified food. Also, in all modified treatments, almost complete removal of the diatom food items by E. vannus was observed. Actual ingestion of $S$. costatum by $E$. vannus was also confirmed by our direct observation of these algal food items in the food vacuoles of the ciliates. These results are in marked contrast to results from controls where higher concentrations of short chains were found at the termination of an experiment (Fig. 2C, D). This phenomenon is possibly attributable to the feeding behavior of ciliates in the controls. When faced with dwindling amounts of $S$. costatum at 'preferred' chain length sizes, $E$. vannus may have fragmented larger chains, thus producing shorter ones, as a result of behavioral activities associated with feeding (Capriulo 1982). Results from Expts 1 and 2 (Figs. 2C, D), where a decrease in the numbers of long chains was observed, support this notion. Such activities could be energetically costly to the ciliates and might be expected to result in lower ciliate growth rates and yields. This interpretation is consistent with our data.

The experiments reported here were designed only to demonstrate whether or not modification of size (with potential concomitant changes in cell quality) of diatom chains influences ciliate population sizes and growth rates. The detailed mechanism by which such enhanced growth occurs is as yet unknown. For example, it is not clear at this time whether reduction of chain length alone or possible treatment-enhanced bacterial growth associated with modified Skeletonema costatum was responsible for differential ciliate growth. It is likely that both factors have a significant influence on ciliate growth. This remains an area of continuing, active research interest to us.

Predator feeding-related modification of prey size is likely to be important at all levels of both planktonic and benthic food webs. For example, it has been shown that certain ciliates produce particles as a by-product of their feeding (Stoecker 1984). These particles are of a size suitable for ingestion by heterotrophic flagellates and may stimulate growth of these heterotrophs. The importance of food size modification to the energy flow and dynamics of all aquatic ecosystems warrants continued investigation, as has already been pointed out by Lubchenco \& Gaines (1981) for intertidal benthic grazers and by Peterson (1975) and Walsh (1976) for nutrient-phytoplankton interactions.

\section{LITERATURE CITED}

Bamforth, S. S. (1985). Ecology of Protozoa. In: Lee, J. J., Hutner, S. H., Bovee, E. C. (eds.) Illustrated guide to the protozoa. Soc. of Protozoologists. Allen Press, Inc., Kansas, p. 8-15

Borror, A. C. (1963). Morphology and ecology of the benthic ciliated protozoa of Alligator Harbor, Florida. Arch. Protistenk. 106: 465-534

Capriulo, G. M. (1982). Feeding of field collected tintinnid microzooplankton on natural food. Mar. Biol. 71: 73-86

Capriulo, G. M., Flanzenbaum, J., Wurster, C. F., Rowland, R. G. (1983). Resistance may be an important mechanism by which marine microbes respond to environmental toxicants. Estuar coast. Shelf Sci. 17: 573-579

Caron, D. A., Davis, P. G., Madin, L. P., Sieburth, J. McN. (1982). Heterotrophic bacteria and bacterivorous protozoa in oceanic macroaggregates. Science 218: 795-797

Deason, E. E. (1980). Potential effect of phytoplankton colony breakage on the calculation of zooplankton filtration rates. Mar. Biol. 57: 279-286

Fenchel, T (1968). The ecology of marine microbenthos. II the food of marine benthic ciliates. Ophelia 5: 73-121

Fenchel, T (1969). The ecology of marine microbenthos. IV structure and function of the benthic ecosystem. Ophelia 6 : $1-182$

Fenchel, T. (1987). Ecology of Protozoa. Springer Verlag, Heidelberg

Kahl, A. (1935). Protozoa, 1: Ciliata. In: F. Dahl (ed.) Die Tierwelt Deutschlands. Verlag Gustav Fischer, Jena, p. 651-886

Lubchenco, J., Gaines, S. D. (1981). A unified approach to marine plant-herbivore interactions. 1. Populations and communities. Ann. Rev. Ecol. Syst. 12: 405-437

O'Connors, H. B. Jr, Small, L. F., Donaghay, P. L. (1976). Particle size modification by two size classes of the estuarine copepod Acartia clausi. Limnol. Oceanogr. 21: 300-308

Peterson, R. (1975). The paradox of the plankton: an equilibrium hypothesis. Am. Nat. 109: 35-49

Provasoli, L. (1963). Growing marine seaweeds. In: Proceedings of the 4 th International Seaweed Symposium. Pergamon Press, New York, p. 9-17

Roman, M. R., Rublee, P. A. (1980). Containment effects in copepod grazing experiments: a plea to end the black box approach. Limnol. Oceanogr. 25: 982-990

Smetacek, V S. (1981). The annual cycle of protozooplankton in the Kiel Bight. Mar. Biol. 63: 1-11

Sokal, R. R., Rohlf, F. J. (1969). Biometry: the principles and practice of statistics in biological research. W. H. Freeman and Co., San Francisco

Stoecker, D. K. (1984). Particle production by planktonic ciliates. Limnol. Oceanogr. 29: 930-940

Turner, J. T., Bruno, S. F., Larson, R. J., Staker, R. D., Sharma, G. M. (1983). Seasonality of plankton assemblages in a temperate estuary. P.S.Z.N.I. Mar. Ecol. 4: 81-99

Verity, P. G., Villareal, T. A. (1986). The relative food value of diatoms, dinoflagellates, flagellates and cyanobacteria for tintinnid ciliates. Arch. Protistenk. 31: 71-84

Walsh, J. J. (1976). Herbivory as a factor in patterns of nutrient utilization in the sea. Limnol. Oceanogr. 21: 1-13

Acknowledgements. This research was supported by a research grant (to G.M.C.) from the Hudson River Foundation for Science and Environmental Research.

This note was presented by Dr M. Levandowsky; it was accepted for printing on May 5, 1988 